\title{
Loyalty, Investment Model and New Media - A Correlation Study in Banking Services in Montenegro
}

e-mail:

bojana.femic@gmail.com;

bojana@ef.ac.me

\author{
${ }^{* *}$ Faculty of Economics \\ Podgorica, University of \\ Montenegro \\ e-mail: \\ misko@ac.me; \\ misko.jovovic@gmail.com
}

Abstract. In this paper we perceived causal relationship between new media through online word of mouth in banking services in Montenegro. Obtained empirical results substantiated validity of the set hypothetical frame, i.e. meaningfulness of the conceptual model that is set.

Keywords: Loyalty, services, banking, new media, investment model, online Word-of-Mouth (WOM)

JEL Classification: M39, G20

\section{Introduction}

Loyalty, investment model and online word of mouth are the concepts that are very well known in the marketing literature. But on the other hand, the relations between the three have not yet been explained enough in academic papers, so this motivated authors to tie the theoretical-hypothetical frame of this research to both existing model of investment and connection of that model to the new media. In that way, a couple of hypothesis were defined which are mutually connected and which were confirmed or refused in the very research, and they show the connection between the use of new media and customer loyalty, as well as the connection between loyalty on one hand and satisfaction level, quality of alternatives, and size of investment on the other. 


\section{Theoretical background}

Investments model that was suggested by Rusbult (Rusbult 1980a, 1980b) takes its origins from the interdependence theory, but it also deals with the size of an investment in the relationship, amount of satisfaction and quality of alternatives. Although it is not very much used in the fields of service marketing and banking, it is very well known in the social psychology literature and similar disciplines (Le and Agnew 2003). That is the main reason why the authors wanted to check whether it is possible to use the Investment model in explaining loyalty in the banking system in Montenegro.

The marketing literature indicates that the amount of satisfaction is the main determinant of loyalty. The Investment model says the same. Also, a significant determinant is the size of an investment in the relationship. That is also shown in numerous literatures where it is explained that investment size and switching costs may influence loyalty (Backman and Crompton 1991; Beerli et al. 2004; Morais et al. 2004). One more variable that could influence the loyalty is the quality of alternatives.

On the other hand, there are so many researchers that have shown through their work the significance of the Word of Mouth (WOM) in marketing (Mattila 2004; Salgaonkar and Mekoth 2004; Hong and Goo 2004; Pullman and Gross 2004; Chung and Darke 2006). The well-known fact in the marketing literature is the significance of loyalty (Rundle-Thiele and Mackay 2001; Oliver 1999). There are some studies that were analyzing the development of loyalty (Srinivasan et al. 2002; Harris and Goode 2004; Auh et al. 2007) and WOM (Smith et al. 2005; Brown et al. 2007; Sen and Lerman 2007) in the online context.

That is the main reason why the concept of loyalty in linked with the online WOM in this research as well. Therefore, having in mind the relevant literature, it could be shown that the loyalty of customers is influenced by their satisfaction, meaning the experience they have had and the word of mouth that is spread online about banking services.

The significance of the word of mouth was the subject of many studies (Godes and Mayzlin 2004). The main research questions were the conditions that give rise to the possibility that the customers will listen strongly to the opinion of other people when they are making the buying decisions. They also deal with the motivation that makes different people share their experience with the products/services and the difference in the power that different people make on their environment. The research has shown one very interesting data and that is that 
customers who started using the services of some company because of WOM in their mind give bigger longtime value to the company than those who started using the company services based on traditional marketing channels (Villanueva, Yoo and Hanssens 2008).

\section{Research model and hypotheses development}

Lately, literature in the field of marketing communication has further separated from the classical models. Thanks to the improvement of information technology, it increasingly leans on modern and fast communications which emphasize the talk between the very customers and the strong impact that conversation has on their behavior.

Starting from the fact that customer loyalty, which refers to their positive attitudes about the company, will lead to the loyalty in behavior, we have derived the following hypotheses:

H1a: Customer loyalty, which refers to their attitudes about the company, will significantly and positively be affected by their level of satisfaction with services or, simply put, increase of service satisfaction increases the level of customer loyalty.

H1b: Customer loyalty, which refers to their attitudes about the company, will significantly and negatively be affected by the quality of alternatives offered by the competition, i.e. increase of quality of alternatives lowers the level of customer loyalty.

H1c: Customer loyalty, which refers to their attitudes about the company, will significantly and positively be affected by the size of investment (time, effort and emotions), i.e. increase of individual investment increases the level of customer loyalty.

For our paper we consider the following hypotheses extremely important:

H2a: Through online WOM, new media significantly affects the level of customer satisfaction.

$\mathrm{H} 2 \mathrm{~b}$ : Through online WOM, new media significantly affects the quality of alternatives. 
H2c: Through online WOM, new media significantly affects the level of investments.

During the execution of the research, we noticed that it would be interesting and important to test the following hypotheses:

H3a: Customer satisfaction will significantly and positively be affected by their perception of quality of the services, or simply put, an increase in perceived quality of services increases the level of customer satisfaction.

H3b: Customer satisfaction will significantly and positively be affected by their perception of service value, i.e. an increase in perceived value increases the level of customer loyalty.

H4a: Online WOM (role of emitter) will significantly and positively be affected by loyalty, that is, an increase in loyalty increases the probability of spreading online WOM.

H4b: Online WOM (role of emitter) will significantly and positively be affected by satisfaction, that is, an increase in satisfaction increases the probability of spreading online WOM.

\section{Methodology}

This testing included examinees who are above 18 and who were using the services of some of Montenegrin banks in the past half a year prior to the testing. Final stratification of the pilot sample was executed on the basis of: gender, age, region in which they live, and marital status. Final sample for this experiment was composed of two subsamples: 1) First subsample was chosen in two stages. In the first stage, polling places were chosen proportionally to its size, and people were chosen in the second stage. Total of 350 questionnaires were distributed according to the above criteria to people from municipalities in all regions of Montenegro. 2) Units of the second subsample were collected by using an online method.

Namely, the questionnaire was put on the SurveyMonkey platform and the link that contained the research was promoted five days using Google advertising. For that purpose three kinds of banners were created. Due to the fact that Google advertising still has low presence in Montenegro, link with the survey appeared even on some pages of the most popular Montenegrin web portals. Since targeting by all parameters, which is used in more developed systems, is not possible 
to execute in Montenegro, the criterion we leaned on the most was the interest of potential target public. In that way, every person in Montenegro who searched for the topics related to the social media, finances, banking, credits, education, investments, business etc., was targeted. The result is that in five days the advertisement was shown 106,032 times, which further resulted in 648 clicks. Of this number, 457 decided to start filling the questionnaire and 366 actually completed it. In conclusion, total of 800 persons were allocated, of which 631 accepted to participate in the survey.

When it comes to the reliability scale, Nunnally and Bernstein (1994) think that coefficient of 0.70 or higher is acceptable, while the coefficient of 0.90 and more is a sign of good reliability. In this research, Cronbach's alpha was at any rate higher than 0.70 , so we can say that the scales used here have shown a reasonable level of internal consistency.

\section{Empirical results}

IBM SPSS Statistics 20 was used for the statistical analysis. Considering the conception of the questionnaire (seven-point Likert scale), nonparametric methods were used for the statistical analysis. The model which will be tested in this research has already been explained.

In order to check the first group of hypotheses that explains the impact of regressor: satisfaction, quality of alternatives, and the level of investment in loyalty, first we considered the simple linear regression, and later the multiple one.

H1a: Customer loyalty, which refers to their attitudes about the company, will significantly and positively be affected by their level of satisfaction with services or, simply put, an increase in service satisfaction increases the level of customer loyalty.

At the beginning, we tested the first hypothesis which explains the relation of loyalty (LOY) as dependent and level of satisfaction (SAT) as independent variable, i.e.:

$$
\mathrm{LOY}=\beta_{1} * \mathrm{SAT}+\mathrm{n}_{1}
$$

The results show that the regression model, which connects satisfaction (SAT) and loyalty $(\mathrm{LOY}=2.49 * \mathrm{SAT}+3.385)$ is statistically valid (ANOVA, $\mathrm{p}<0.0001)$. Slope coefficient $\left(\beta_{1}=2.49\right)$ is statistically significantly different from $0(t=24.441$, 
$\mathrm{p}<0.0001)$. This shows us that an increase in satisfaction by 1 , increases loyalty by 2.49 .

In this model of simple linear regression, determination coefficient is $\mathrm{R}^{2}=0.493$, i.e. $49.3 \%$ of variability in loyalty can be explained with variability of satisfaction, while the remaining $50.7 \%$ of variability is the aftermath of some other factors.

H1b: Customer loyalty, which refers to their attitudes about the company, will significantly and negatively be affected by the quality of alternatives offered by the competition, i.e. an increase in the quality of alternatives lowers the level of customer loyalty.

Beside satisfaction, quality of alternatives (QUAL) affects the loyalty (LOY) as well, so we considered another simple linear regression, i.e.:

$$
\mathrm{LOY}=\beta_{2}{ }^{\star} \mathrm{QUAL}+\mathbf{n}_{2}
$$

Results show that the regression model which connects quality of alternatives (QUAL) and loyalty ( $\left.\mathrm{QOY}=-0.428^{\star} \mathrm{QUAL}+49.353\right)$ is statistically valid (ANOVA, $\mathrm{p}<0.0001)$. Slope coefficient $\left(\beta_{2}=-0.428\right)$ is statistically significantly different from $0(\mathrm{t}=-4.6, \mathrm{p}<0.0001)$. This shows us that an increase in the quality of alternatives by 1 , lowers loyalty by 0.428 .

In this model, determination coefficient is $\mathrm{R}^{2}=0.033$, which shows that only $3.3 \%$ of variability in loyalty is explained with the quality of alternatives variability, while the remaining $96.7 \%$ variability is the aftermath of some other factors. We can already see now that loyalty is much better explained with satisfaction than with quality of alternatives, which is expected.

H1c: Customer loyalty, which refers to their attitudes about the company, will significantly and positively be affected by the size of investment (time, effort and emotions), i.e. an increase in individual investment increases the level of customer loyalty.

Besides already mentioned variables, loyalty (LOY) is also affected by the size of investment (INV) which is explained through effort, time, money, and emotions which customer puts into the relationship with the company, so we tested that simple linear regression as well, i.e.:

$$
\mathrm{LOY}=\boldsymbol{\beta}_{3}{ }^{\star} \mathrm{INV}+\mathbf{n}_{3}
$$


Results also show that this regression model which connects the level of investment $(\mathrm{INV})$ and loyalty $\left(\mathrm{LOY}=0.802^{\star} \mathrm{INV}+11.441\right)$ is statistically valid (ANOVA, $\mathrm{p}<0.0001)$. Slope coefficient $\left(\beta_{3}=0.802\right)$ is statistically significantly different from $0(t=21.914, \mathrm{p}<0.0001)$. This shows us that an increase in the level of investment by 1 , increases loyalty by 0.802 .

Determination coefficient in this model is $\mathrm{R}^{2}=0.433$, which shows that $43.3 \%$ of variability in loyalty can be explained with variability of the level of investment, and the remaining $56.7 \%$ of variability is the aftermath of some other factors.

Based on everything that is stated, we can conclude that customer loyalty is significantly and positively affected by the level of service satisfaction and level of investment in the relationship with the company, while quality of alternatives offered by the competition significantly and negatively affects the customer loyalty. That confirms the first set of hypotheses. Table 1 shows a summary of already explained parameters from simple regression models in which loyalty is a dependent variable.

Table 1: Simple regression models with loyalty as dependent variable

\begin{tabular}{cccc}
\hline Symbol & $\beta$ & $p$ & $\mathrm{R}^{2}$ \\
\hline SAT & 2.49 & $<0.0001$ & 0.49 \\
\hline QUAL & -0.428 & $<0.0001$ & 0.03 \\
\hline INV & 0.802 & $<0.0001$ & 0.43 \\
\hline
\end{tabular}

After this, we decided to test the multiple linear regression where the regressors were: satisfaction, quality of alternatives, and level of investment, and loyalty as a dependent variable. Table 2 shows the slope coefficient, statistical significance, and determination coefficient which we obtained for that model.

Table 2: Multiple linear regression

\begin{tabular}{cccc}
\hline Symbol & $\beta$ & $p$ & $\mathrm{R}^{2}$ \\
\hline SAT & 1.721 & $<0.0001$ & \\
\hdashline QUAL & -0.27 & $<0.0001$ & 0.614 \\
\hline INV & 0.467 & $<0.0001$ & \\
\hline
\end{tabular}

As we can see, the determination coefficient significantly increases and amounts to $\mathrm{R}^{2}=0.614$, which shows that $61.4 \%$ of variability in loyalty can be explained with satisfaction variability, quality of alternatives, and the level of investment, and the remaining $38.6 \%$ of variability is the aftermath of some other factors. 


\section{H2a: Through online WOM, new media significantly affects the level of cus- tomer satisfaction.}

The following set of hypotheses that we tested refers to the impact of new media through online WOM on the level of satisfaction, quality of alternatives, and the level of investment. In the first hypothesis, we tested the impact of online WOM (OWS) on satisfaction (SAT), thus we examined simple linear regression, i.e.:

$$
\mathrm{SAT}=\boldsymbol{\beta}{ }^{\star} \mathrm{OWS}+\mathbf{n}
$$

The results show that the regression model which connects online WOM (OWS) and satisfaction (SAT $=0.057^{\star} \mathrm{OWS}+13.779$ ) is statistically valid (ANOVA, $\mathrm{p}<0.0001)$. Slope coefficient $(\beta=0.057)$ is statistically significantly different from $0(\mathrm{t}=2.981, \mathrm{p}<0.001)$. That shows us that an increase of online word of mouth by 1 , leads to an increase of satisfaction by 0.057 .

In this model, determination coefficient is $\mathrm{R}^{2}=0.014$, which shows that only $1.4 \%$ of variability in satisfaction is explained with the variability of online WOM, while the remaining $98.6 \%$ of variability is the aftermath of some other factors.

H2b: Through online WOM, new media significantly affects the quality of alternatives.

Simple regression linear model, which connects online WOM as independent and quality of alternatives as dependent variable, is not statistically valid, which further indicates that this hypothesis is not supported.

H2c: Through online WOM, new media significantly affects the level of investments.

Further on we tested the impact of online WOM (OWS) on level of investment (INV), thus we examined the following simple linear regression:

$$
\mathrm{INV}=\boldsymbol{\beta} \star \mathrm{OWS}+\mathbf{n}
$$

The results show that regression model which connects online WOM (OWS) and level of investment (INV $\left.=0.255^{\star} \mathrm{INV}+31.258\right)$ is statistically valid (ANOVA, $\mathrm{p}<0.0001)$. Slope coefficient $(\beta=0.255)$ is statistically significantly different from $0(\mathrm{t}=4.666, \mathrm{p}<0.001)$. This proves that an increase in online word of mouth by 1 leads to an increase in the level of investment by 0.255 . 
In this model, determination coefficient is $\mathrm{R}^{2}=0.034$, which shows that only $3.4 \%$ of variability in satisfaction is explained with the variability of online WOM, while the remaining $96.6 \%$ of variability is the aftermath of some other factors.

H3a: Customer satisfaction will significantly and positively be affected by their perception of the quality of services or, simply put, an increase in the perceived quality of services increases the level of customer satisfaction.

In the following set of hypotheses, we will observe satisfaction as dependent variable. In the first hypothesis we will measure the impact of perceived quality of services (QUA) on satisfaction (SAT), so we set the following simple linear regression:

$$
\mathrm{SAT}=\boldsymbol{\beta} * \mathrm{QUA}+\mathbf{n}
$$

The results show that this regression model, which connects perceived quality of services (QUA) and satisfaction $\left(\mathrm{SAT}=0.893^{\star} \mathrm{QUA}+5.884\right)$ is statistically valid (ANOVA, $\mathrm{p}<0.0001)$. Slope coefficient $\left(\beta_{3}=0.893\right)$ is statistically significantly different from $0(t=21.057, \mathrm{p}<0.0001)$. This $\left(\beta_{3}=0.893\right)$ shows us that an increase of the perceived quality of services by 1 leads to an increase in satisfaction of 0,893 .

In this model, determination coefficient is $\mathrm{R}^{2}=0.419$, which shows that $41.9 \%$ of variability in satisfaction can be explained by the variability of level of perceived quality, and the remaining $58.1 \%$ of variability is the aftermath of some other factors.

H3b: Customer satisfaction will significantly and positively be affected by their perception of service value, i.e. an increase of perceived value increases the level of customer loyalty.

According to this hypothesis, we test the impact of perceived value of services (VAL) on satisfaction (SAT), so we set the following simple linear regression:

$$
\mathrm{SAT}=\boldsymbol{\beta} * \mathrm{VAL}+\mathbf{n}
$$

The results show that this regression model, which connects the perceived value of services $(\mathrm{VAL})$ and satisfaction $\left(\mathrm{SAT}=0.518^{\star} \mathrm{VAL}+4.862\right)$ is statistically valid (ANOVA, $\mathrm{p}<0.0001)$. Slope coefficient $\left(\beta_{3}=0.518\right)$ is statistically significantly different from $0(t=25.283, p<0.0001)$. This shows that an increase in the perceived value of services by 1 leads to an increase in satisfaction by 0.518 . 
In this model, determination coefficient is $\mathrm{R}^{2}=0.51$, which shows that $51 \%$ of variability in satisfaction is explained with variability of the level of perceived value of services, and the remaining $49 \%$ of variability is the aftermath of some other factors.

From the above stated we can conclude that customer satisfaction is significantly and positively affected by the level of perceived quality and perceived value of services. With that, this set of hypotheses is supported as well. Table 3 shows a summary of already explained parameters from simple regression models in which satisfaction is the dependent variable.

Table 3: Simple regression models with satisfaction as dependent variable

\begin{tabular}{cccc}
\hline Symbol & $\beta$ & $p$ & $\mathrm{R}^{2}$ \\
\hline QUA & 0.893 & $<0.0001$ & 0.419 \\
\hline VAL & 0.518 & $<0.0001$ & 0.51 \\
\hline
\end{tabular}

After this we decided, similar to the testing of the first set of hypotheses, to test the multiple linear regression where the regressors were: perceived quality and perceived value of services. Table 4 shows the slope coefficient, statistical significance, and determination coefficient which we obtained for that model.

Table 4: Multiple linear regression

\begin{tabular}{cccc}
\hline Symbol & $\beta$ & $p$ & $\mathrm{R}^{2}$ \\
\hline QUA & 0.431 & $<0.0001$ & 0.565 \\
\hline VAL & 0.369 & $<0.0001$ & \\
\hline
\end{tabular}

As we can see, determination coefficient increases and it amounts to $\mathrm{R}^{2}=0.565$, which shows that $56.5 \%$ of variability in satisfaction can be explained with the variability of perceived quality and perceived value of services, and the remaining $43.5 \%$ of variability is the aftermath of some other factors.

H4a: Online WOM (role of emitter) will significantly and positively be affected by loyalty, that is, an increase in loyalty increases the probability of spreading online WOM.

In this set of hypotheses, WOM is the dependent variable, in the sense of preparedness to spread the 0word of mouth about the company. Primarily, we will test the impact of loyalty (LOY) on online WOM (OWS), so we set the following simple linear regression:

$$
\text { OWS }=\beta^{\star} \text { LOY }+\mathbf{n}
$$


The results show that this regression model, which connects loyalty (LOY) and preparedness to spread online WOM $\left(\mathrm{OWS}=0.063^{\star} \mathrm{LOY}+17.049\right)$ is statistically valid (ANOVA, $\mathrm{p}<0.0001)$. Slope coefficient $(\beta=0.063)$ is statistically significantly different from $0(\mathrm{t}=2.697, \mathrm{p}<0.01)$. This shows that an increase in loyalty by 1 leads to an increase in preparedness to spread online WOM by 0.063 .

In this model, the determination coefficient is $\mathrm{R}^{2}=0.010$, which shows that only $1 \%$ of variability in preparedness to spread online WOM can be explained with the variability of loyalty, while the remaining $99 \%$ of variability is the aftermath of some other factors.

H4b: Online WOM (role of emitter) will significantly and positively be affected by satisfaction, that is, an increase in satisfaction increases the probability of spreading online WOM.

Further on, we tested the impact of satisfaction (SAT) on online WOM (OWS), so we set the following simple linear regression:

$$
\text { OWS }=\beta{ }^{*} \mathrm{SAT}+\mathbf{n}
$$

The results obtained show that this regression model, which connects satisfaction (SAT) and preparedness to spread online WOM (OWS $\left.=0.251^{\star} \mathrm{SAT}+15.875\right)$ is statistically valid (ANOVA, $\mathrm{p}<0.0001)$. Slope coefficient $(\beta=0.251)$ is statistically significantly different from $0(t=2.981, \mathrm{p}<0.005)$. This shows that an increase in satisfaction by 1 , increases the preparedness to spread online WOM by 0.251 .

In this model, determination coefficient is $\mathrm{R}^{2}=0.014$, which shows that only $1.4 \%$ of variability in preparedness to spread online WOM can be explained with variability of satisfaction, while the remaining $98.6 \%$ of variability is the aftermath of some other factors.

\section{Conclusions}

In this paper we perceived the causal relationship between loyalty, satisfaction, the quality of alternatives, investment size, and new media through online word of mouth in banking services in Montenegro. Obtained empirical results substantiated the validity of the set hypothetical frame, i.e. meaningfulness of the conceptual model that is set. More precisely, results substantiated that customer loyalty, which refers to their attitudes about the company, will significantly and positively be affected by their level of satisfaction with the services and the size 
of investment, and negatively affected by the quality of alternatives offered by the competition.

Also, the results show that through online WOM, new media significantly affects the level of customer satisfaction and investment size, but not the quality of alternatives. They also show that customer satisfaction will be significantly and positively affected by their perception of quality of the services and their perception of the service value. With regard to the online WOM, this research shows that online WOM (role of emitter) will be significantly and positively affected by loyalty and satisfaction. As expected, results obtained in this way have certain theoretical and practical implications.

With technology and communication development there is also a growth of impact which online Word-of-Mouth (WOM) has on the customer behavior. The impact of online WOM on customer loyalty in the service sector, in this case in the banking sector in Montenegro, shows the differences regarding the impact that depend on the source of the message (whether it comes from an expert or someone who does not fall into that category and can be a friend or an acquaintance), message valence (positive or negative), and the manner in which the message is written, that could be the topics of another paper. 


\section{References}

1. Auh, S., Bell, S.J., McLeod, C.S. and Shih, E. (2007). Co-production and customer loyalty in financial services. Journal of Retailing, Vol. 88 No. 3, 359-70.

2. Backman, S. J., and J.L. Crompton (1991). The Usefulness of Selected Variables for Predicting Activity Loyalty. Leisure Sciences, 13: 205-20.

3. Beerli, A., J.D. Martin, and A. Quintana (2004). A Model of Customer Loyalty in the Retailing Banking Market. European Journal of Marketing, 38 (1/2): 253-75.

4. Brown, J., Broderick, A.J. \& Lee, N. (2007) Word of mouth communication within online communities: conceptualizing the online social network. Journal Of Interactive Marketing. Vol. 21. No. 3

5. Chung, C.M.Y. and Darke, P.R. (2006). The consumer as advocate: selfrelevance, culture and word-of-mouth. Marketing Letters, Vol. 17, 269-79.

6. Godes, D. and Mayzlin, D. (2004). Using online conversations to study word-of-mouth communications. Marketing Science, Vol. 23 No. 4, pp 54560 .

7. Harris, L.C., \& M.M.H. Goode (2004). The Four Levels of Loyalty and the Pivotal Role of Trust: A Study of Online Service Dynamics. Journal of Retailing, Vol. 80

8. Hong, S.-C. and Goo, Y.J.J. (2004). A causal model of customer loyalty in professional service firms: an empirical study. International Journal of Management, Vol. 21 No. 4, pp. 531-40.

9. Le, B., and C. R. Agnew (2003). "Commitment and Its Theorized Determinants: A Meta-Analysis of the Investment Model.” Personal Relationships, 10: 37-57

10. Mattila, A.S. (2004). The impact of service failures on customer loyalty: the moderating role of affective commitment. International Journal of Service Industry Management, Vol. 15 No. 2, 134-49.

11. Morais, D. B., M. J. Dorsch, and S. J. Backman (2004). Can Tourism Providers Buy Their Customers' Loyalty? Examining the Influence of Customer-Provider Investments on Loyalty. Journal of Travel Research, 42 (3): 235-43.

12. Nunnally, J. \& Bernstein, I. (1994) Psychometric Theory (3rd ed). New York: McGraw-Hill

13. Oliver, R.L. 1999. Whence consumer loyalty? Journal of Marketing, Vol. 63, 33-44.

14. Pullman, M.E. and Gross, M.A. (2004). Ability of experience design elements to elicit emotions and loyalty behaviors. Decision Sciences, Vol. 35 No. 3, 551-78. 
15. Rundle-Thiele, S. and Mackay, M.M. 2001. Assessing the performance of brand loyalty measures, Journal of Services Marketing, Vol. 15 No. 7, 529-46.

16. Rusbult, C. E. (1980a). Commitment and satisfaction in romantic associations: a test of the Investment model. Journal of Experimental Social Psychology, 16: 172-86.

17. Rusbult, C. E. (1980b). "Satisfaction and Commitment in Friendships." Representative Research in Social Psychology, 11: 96-105.

18. Salgaonkar, P.B. and Mekoth, N. (2004). Patient as a source of recommendation and its influence on another patient's loyalty to the physician: an exploratory empirical study. Journal of Consumer Satisfaction, Dissatisfaction and Complaining Behavior, Vol. 17, pp. 16-26.

19. Sen, S. and Lerman, D. (2007). Why are you telling me this? An examination into negative consumer reviews on the web. Journal of Interactive Marketing, Vol. 21 No. 4, pp. 76-94.

20. Smith, D., Menon, S. \& Sivakumar, K. (2005) Online peer and editorial recommendations, trust, and choice in virtual markets. Journal of Interactive Marketing. Vol. 19 No. 3

21. Srinivasan, S. S., R. Anderson, \& K. Ponnavolu. (2002). Customer Loyalty in E-Commerce: An Exploration of Its Antecedents and Consequences. Journal of Retailing, Vol. 78

22. Villanueva, J., Shijin Yoo, and Dominique M. Hanssens (2008). The Impact of Marketing-Induced Word-of-Mouth Customer Acquisition on Customer Equity Growth. Journal of Marketing Research: February 2008, Vol. 45, No. 1, pp. 48-59. 